\section{PRODUCCIÓN CIENTÍFICA DE LOS MIEMBROS DE LA ACADEMIA NACIONAL DE CIENCIAS}

\section{SCIENTIFIC PRODUCTION OF MEMBERS OF THE NATIONAL ACADEMY OF SCIENCES}

\author{
Gustavo F. Gonzales ${ }^{1,2, a}$, Christian Valqui ${ }^{2,3, b}$, \\ Jorge Chau ${ }^{2,4, c}$
}

Sr. Editor. En reciente carta al editor se menciona la producción científica de los miembros vitalicios de la Academia Nacional de Investigadores Médicos ${ }^{(1)}$. De los treinta miembros vitalicios doce publicaron un artículo una vez en su vida, y cuatro al menos un artículo en los dos últimos años. En la carta se menciona que los resultados concuerdan con las investigaciones realizadas previamente en términos de la baja producción científica ${ }^{(2)}$.

Enestaoportunidad leescribimos para resaltarla producción científica de los miembros de número de la Academia Nacional de Ciencias. La Academia Nacional de Ciencias (ANC) fue fundada el 6 de agosto de 1938 por un grupo de 35 distinguidos científicos peruanos, originalmente con el nombre "Academia Nacional de Ciencias Exactas, Física y Naturales de Lima", para promocionar la investigación científica y la difusión del conocimiento científico. Fue reconocida por Decreto Supremo el 23 de octubre de 1939 y, también por Decreto Supremo, el 2 de diciembre de 1966 cambia su denominación a ANC. En la actualidad, la ANC tiene 60 miembros como académicos de número quienes, para acceder a dicha distinción, son invitados por sus méritos personales y profesionales. Este año, 2014, la Academia cumple 75 años del reconocimiento como tal por el Gobierno peruano.

Se ha realizado un análisis de la producción científica de sus académicos de número basado en tres marcadores: número de publicaciones, número de citaciones e índice $\mathrm{H}$. Este último es un número $n$ calculado a partir de las citas que tiene cada artículo publicado por el autor, y significa que el autor tiene $n$ artículos publicados que han sido citados al menos $n$ veces cada uno. Sirve para comparar simultáneamente la cantidad y calidad de la producción de científicos de un mismo campo.

\footnotetext{
Universidad Peruana Cayetano Heredia. Lima, Perú.

Academia Nacional de Ciencias. Lima, Perú.

Pontificia Universidad Católica del Perú. Lima, Perú.

Instituto Geofísico del Perú. Lima, Perú.

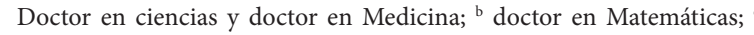
doctor en Física

Recibido: 29-01-14 Aprobado: 12-02-14
}

Citar como: Gonzales GF, Valqui C, Chau J. Producción científica de los miembros de la Academia Nacional de Ciencias [carta]. Rev Peru Med Exp Salud Publica. 2014;31(2):396.
Tabla 1. Publicaciones en revistas indizadas a Scopus de los académicos de número de la Academia Nacional de Ciencias

\begin{tabular}{lcc}
\hline \multicolumn{1}{c}{ Publicación } & Número & Promedio \\
\hline Artículos indizados en Scopus & 1752 & 29,2 \\
Artículos en los últimos 5 años & 416 & 6,9 \\
Artículos en los últimos 2 años & 168 & 2,8 \\
Citaciones & 48960 & 816 \\
Índice H & & 7,7 \\
\hline
\end{tabular}

*2012-2013

Para este propósito se realizó una búsqueda de las publicaciones científicas indizadas en la base de datos de Scopus. Los académicos de número han publicado 1752 artículos indizados con 48960 citaciones. En total los académicos han publicado 416 artículos indizados en los últimos 5 años y 168 en los últimos 2 años (Tabla 1). De los 60 académicos, $49(81,7 \%)$ tienen al menos un artículo publicado en su vida en una revista indizada por Scopus, 39 (65\%) tienen un índice $H \geq 2$, y $12(20 \%)$ de ellos tienen un índice $\mathrm{H} \geq 12$.

La ANC es una institución que tiene entre otros los siguientes fines: 1 . Promover el desarrollo de la ciencia y sus aplicaciones, de modo de contribuir al incremento de conocimientos, y que estos sean útiles para satisfacer, en particular, la necesidades de la sociedad peruana. 2 . Fomentar la excelencia en la enseñanza de estudios de la ciencia, a todo nivel. 3. Auspiciar las publicaciones de calidad en ciencia y tecnología. 4. Alentar a los científicos peruanos a publicar en revistas de circulación internacional. A sus 75 años, la ANC da evidencia de la calidad profesional de sus miembros como se traduce en sus publicaciones científicas $y$, con ello, dar fe de su capacidad para el cumplimiento de los fines para lo cual fue creado.

Fuentes de financiamiento: autofinanciado.

Conflictos de Interés: los autores son miembros de la Junta Directiva de la Academia Nacional de Ciencias.

\section{REFERENCIAS BIBLIOGRÁFICAS}

1. Mayta-Tristán P, Pereyra-Elías R, Mejía CR. Producción científica de los miembros vitalicios de la Academia Nacional de Investigadores Médicos [carta]. Rev Per Med Exp Salud Publica. 2013;30(4):720-2.

2. Huamaní C, Gonzales G, Curioso WH, Pacheco-Romero J. Redes de colaboración y producción sudamericana en medicina clínica, ISI Current Contents 2000-2009. Rev Med Chile. 2012;140(4):466-75.

Correspondencia: Gustavo Gonzales Rengifo

Dirección: Av. Honorio Delgado 430. Lima 31, Perú

Teléfono: 3190000 anexo 2535

Correo electrónico:gustavo.gonzales@upch.pe 